\title{
Evaluation and Study of Solitary Thyroid Nodule in 102 Cases
}

\section{Sourav Banerjee ${ }^{1 *}$, Dipesh Darji ${ }^{2}$, Kalpesh Patel ${ }^{3}$, Vaishali Patel ${ }^{1}$ and Vaidik Chauhan ${ }^{4}$}

${ }^{1} 2^{\text {nd }}$ Year Resident, B.J Medical College, Ahmedabad, Gujarat, India

${ }^{2}$ Assistant Professor, B.J Medical College, Ahmedabad, Gujarat, India

${ }_{3}^{3}$ Associate Professor, B.J Medical College, Ahmedabad, Gujarat, India

${ }^{4}$ Senior Resident, B.J Medical College, Ahmedabad, Gujarat, India

*Corresponding Author: Sourav Banerjee, $2^{\text {nd }}$ Year Resident, B.J Medical College,

Ahmedabad, Gujarat, India.

\author{
Received: April 08, 2020 \\ Published: June 17, 2020 \\ (C) All rights are reserved by Sumana CV., \\ et al.
}

\begin{abstract}
Aims and Objective: Evaluation of Solitary thyroid nodule to differentiate benign from malignant lesion and establish correlation between USG, FNAC and Histopathological examination (HPE).

Materials and Methods: Study design: It is a prospective study of patients admitted in ENT department of Civil Hospital Ahmadabad for solitary thyroid nodule from August 2018 to October 2019.

Study Tools: A total 102 patients were evaluated. Help was taken from radiology department for USG neck screening and also from pathology department where FNAC and HPE findings are correlated.

Observation and Results: Out of 21 cases diagnosed as malignant on ultrasound, 18 were confirmed as malignant on FNAC, 3 were found to be benign. So, correlation between USG and FNAC is $85.7 \%$.

Out of 21 cases diagnosed as malignant on ultrasound, 16 were confirmed as malignant by HPE, rest were found to be benign. So, correlation between USG and HPE is 76.1\%.

Out of 18 cases diagnosed as malignant on FNAC, 16 were confirmed by histopathology postoperatively. So, correlation between FNAC AND HPE is $88.8 \%$.

Conclusion: In our study correlation between USG and FNAC was $85.7 \%$. Correlation between FNAC and HPE is $88 \%$. Fine-needle aspiration cytology is recommended to be a cost-effective procedure in the initial assessment and management of thyroid nodules $[3,6]$.

Detecting malignancy preoperatively allows total thyroidectomy in a single operation without the need of removal of remnant thyroid in second surgery.

Keywords: Solitary Thyroid Nodule; Benign; Malignant; USG; HPE; FNAC
\end{abstract}

\section{Introduction}

Thyroid gland is an endocrine gland consisting of two lobes connected by an isthmus.

Thyroid nodules are nodules (raised areas of tissue or fluid) which commonly arise within an otherwise normal thyroid gland [1].

Thyroid nodules (TNs) are among the common diseases of the endocrine system, with 3\% - 7\% prevalence by palpation [2].

Solitary thyroid nodule is a distinct lesion in thyroid that is palpably or radiologically distinct from thyroid parenchyma.

\section{Materials and Methods}

It is a prospective study of 102 patients admitted in ENT department of Civil Hospital Ahmadabad for solitary thyroid nodule from 2018 to 2019.
Help was taken from radiology department for USG neck screening and also from pathology department where FNAC and HPE findings are correlated.

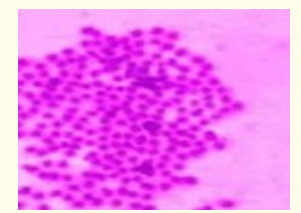

Figure 1: FNAC of colloid goitre.

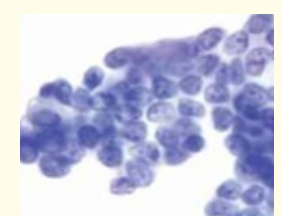

Figure 2: HPE of papillary thyroid carcinoma. 
Inclusion criteria:

- $\quad$ Patient with clinically palpable single thyroid nodule.

- $\quad$ Age group 11 to 75 years.

- $\quad$ Euthyroid patients.

Exclusion criteria:

- $\quad$ Swelling in neck which moves with protrusion of tongue. E.g. Thyroglossal duct cyst.

- $\quad$ Patient who denies proper history.

- Patient who denies consent for surgery.

- Patient without next of kin.

- Anaplastic carcinoma.

Observation and Results

Age wise distribution

Sex wise distribution

\begin{tabular}{|c|c|}
\hline Age (in years) & No \\
\hline$<=20$ & 12 \\
\hline $21-30$ & 25 \\
\hline $31-40$ & 43 \\
\hline $41-50$ & 14 \\
\hline$>50$ & 08 \\
\hline
\end{tabular}

Table 1

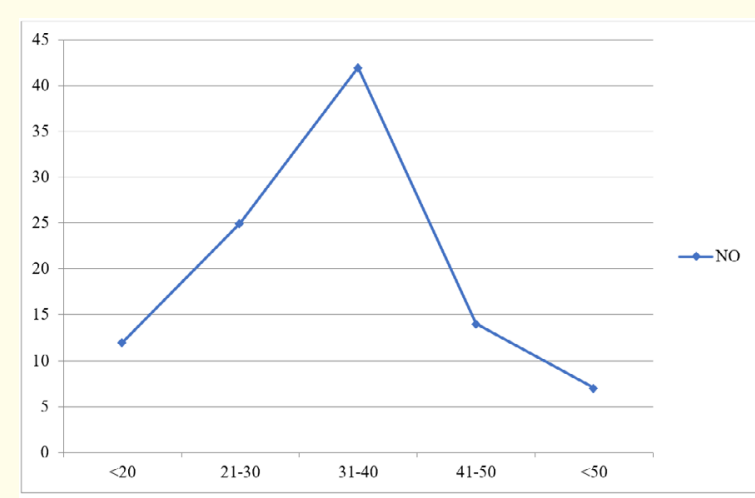

Figure A

Distribution of lesion on USG according to TIRADS

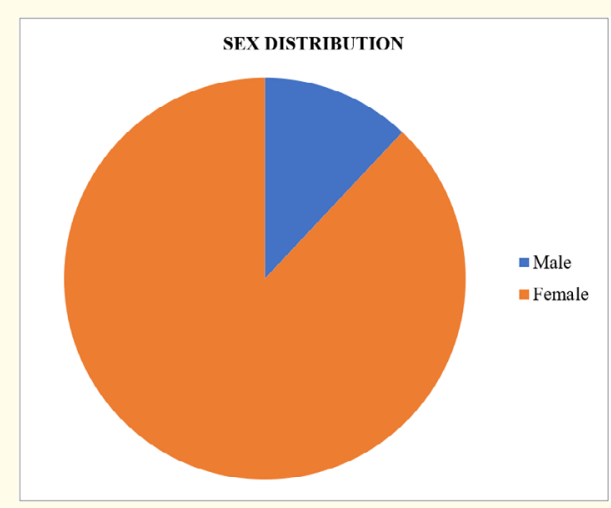

Figure B

\begin{tabular}{|l|c|c|}
\hline \multicolumn{1}{|c|}{ Classification } & Category & No. \\
\hline $\begin{array}{l}\text { Highly suspicious } \\
\text { (TIRAD5) }\end{array}$ & $\begin{array}{c}\text { Hypoechoic solid nodule } \\
\text { Irregular margin } \\
\text { Microcalcification } \\
\text { Extra thyroid extension } \\
\text { Increased vascularity }\end{array}$ & \\
\hline $\begin{array}{l}\text { Intermediate suspicion } \\
\text { (TIRAD4) }\end{array}$ & $\begin{array}{c}\text { Hypoechoic solid nodule } \\
\text { Smooth margin }\end{array}$ & 11 \\
\hline Low suspicion (TIRAD3) & Hyper echoic solid nodule & 64 \\
\hline Very low suspicion (TIRAD2) & Partially cystic nodule & 6 \\
\hline Benign (TIRAD1) & Purely cystic nodule & 0 \\
\hline
\end{tabular}

Table 2

Distribution of lesion ACC to Bethesda system for thyroid cytology

\begin{tabular}{|l|c|c|}
\hline \multicolumn{2}{|c|}{ Bethesda system for thyroid cytology } & No. \\
\hline Category 1 & Cystic fluid only & 0 \\
\hline Category 2 & $\begin{array}{c}\text { Benign follicular nodule, Hashimoto's thyroid- } \\
\text { itis, Granulomatous thyroiditis }\end{array}$ & 79 \\
\hline Category 3 & Atypia of undetermined significance & 5 \\
\hline Category 4 & Follicular neoplasm & 7 \\
\hline Category 5 & Suspicious of medullary or papillary carcinoma & 6 \\
\hline Category 6 & $\begin{array}{c}\text { Medullary carcinoma, papillary carcinoma, } \\
\text { poorly differentiated }\end{array}$ & 5 \\
\hline
\end{tabular}

Table 3

Histopathological diagnosis

\begin{tabular}{|c|c|}
\hline HPE & No \\
\hline Colloid/Nodular Goiter & 64 \\
\hline Hyperplastic Nodule & 8 \\
\hline Hashimoto's Thyroiditis & 2 \\
\hline Adenomatous Goiter & 12 \\
\hline Follicular Carcinoma & 9 \\
\hline Papillary Carcinoma & 5 \\
\hline Medullary Carcinoma & 2 \\
\hline
\end{tabular}

Table 4

Comparison of benign to malignant result on HPE in different studies

\begin{tabular}{|l|c|c|c|}
\hline \multicolumn{1}{|c|}{ Study } & Benign & Malignant & Ratio \\
\hline Tabaqchali., et al. & 145 & 94 & $1.5: 1$ \\
\hline Kamal., et al. & 159 & 22 & $7: 1$ \\
\hline Safirullah., et al. & 265 & 35 & $7.5: 1$ \\
\hline Maddineni R., et al. & 82 & 18 & $4.5: 1$ \\
\hline Mehta S., et al. & 42 & 8 & $5: 1$ \\
\hline Our study & 84 & 16 & $5.2: 1$ \\
\hline
\end{tabular}

Table 5 
Out of 21 cases diagnosed as malignant on ultrasound, 18 were confirmed as malignant on FNAC, 3 were found to be benign. So, correlation between USG and FNAC is $85.7 \%$.

Out of 21 cases diagnosed as malignant on ultrasound, 16 were confirmed as malignant by HPE, rests were found to be benign. So, correlation between USG and HPE is $76.1 \%$.

Out of 18 cases diagnosed as malignant on FNAC, 16 were confirmed by histopathology postoperatively. So, correlation between FNAC AND HPE is $88.8 \%$.

\section{Discussion and Conclusion}

Thyroid nodules are more common in females as noted in the present study $[3,5]$.

In our study correlation between USG and FNAC was 85.7\%. Correlation between USG and HPE is $76.1 \%$. Correlation between FNAC and HPE is $88 \%$.

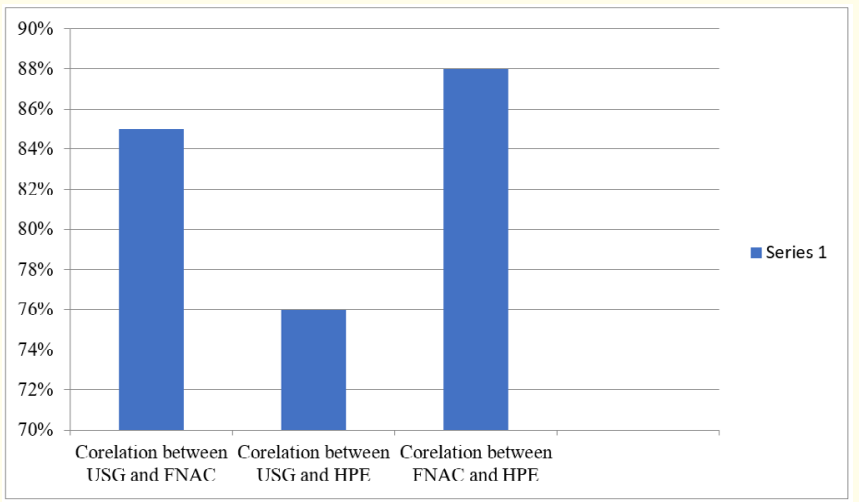

Figure C

FNAC is recommended to be a cost-effective procedure in the initial assessment and management of thyroid nodules $[3,6]$.

Detecting malignancy preoperatively allows total thyroidectomy in a single operation without the need of removal of remnant thyroid in second surgery.

Overall incidence of malignancy in thyroid swelling varies from $10 \%$ to $30 \%$ acc to various studies [4]. In our study is $16 \%$ which is comparable to Mehta S., et al.

\section{Bibliography}

1. “New York Thyroid Center: Thyroid Nodules” (2010).

2. Hegedus L. "The thyroid nodule". New England Journal of Medicine 351 (2004): 1764-1771.

3. Tai JD., et al. "Risk factors for malignancy in patients with solitary thyroid nodules and their impact on the management". Journal of Cancer Research and Therapeutics 8.3 (2012): 379383.
4. Harrison BJ., et al. "Disorders of thyroid gland". In: Cuschieri A, Moossa AR, editors. Essential Surgical Practice. $4^{\text {th }}$ edition. London: Arnold (2002): 95-110.

5. Mazzaferri EL. "Management of a solitary thyroid nodule". New England Journal of Medicine 328.8 (1993): 553-559.

6. Iqbal M., et al. "Carcinoma thyroid in multi and uninodular goiter". Journal of the College of Physicians and Surgeons Pakistan 20.5 (2010): 310-312.

\section{Assets from publication with us}

- Prompt Acknowledgement after receiving the article

- Thorough Double blinded peer review

- Rapid Publication

- Issue of Publication Certificate

- High visibility of your Published work

Website: https://www.actascientific.com/

Submit Article: https://www.actascientific.com/submission.php Email us: editor@actascientific.com

Contact us: +919182824667 